\title{
COMPARATIVE STUDY OF ORAL ANTIDIABETIC THERAPY AND INSULIN THERAPY ON HEPATIC STEATOSIS IN PATIENTS WITH TYPE 2 DIABETES MELLITUS
}

\author{
ANICA HOZA, CORINA MOLDOVAN, DORINA MARIA FĂRCAȘ, ANNAMARIA PALLAG *, \\ SEBASTIAN NEMETH, FELICIA MARC
}

Faculty of Medicine and Pharmacy, University of Oradea, Romania

*corresponding author: annamariapallag@gmail.com

Manuscript received: January 2018

\begin{abstract}
In type 2 diabetes mellitus (DM) patients, hepatic steatosis is present in a much higher proportion than in healthy people. In this study, we have evaluated the presence of steatosis in patients with type $2 \mathrm{DM}$, and whether this may be correlated with the type of treatment that patients are using, either with oral antidiabetics (OAD), or with insulin therapy +/- OAD. In the same time, steatosis has been correlated with nutritional status, metabolic control, and lipidic profile. The results showed that patients treated with insulin, exhibited hepatic steatosis in a statistically significant lower percent than patients treated with OAD. This finding is maintained after the correlation with weight status or metabolic control.
\end{abstract}

\section{Rezumat}

La pacienții cu diabet zaharat (DZ) de tip 2, steatoza hepatică (SH) este prezentă într-o proporție mult mai mare decât la persoanele sănătoase. În acest studiu, am urmărit prezența steatozei (prin examinare ecografică) la pacienții cu DZ tip2 și dacă aceasta se poate corela cu tipul de tratament al pacienților, fie cu antidiabetice orale (ADO), fie cu insulinoterapie +/ADO. De asemenea, steatoza a fost corelată cu statusul nutriţional, controlul metabolic şi profilul lipidic. Rezultatele au arătat că pacienții trataţi cu insulină, au prezentat SH în procent mai mic, semnificativ statistic. Această constatare s-a menținut și după corelarea cu statusul ponderal sau controlul metabolic. Explicația rezultatelor mai bune la pacienții tratați prin insulinoterapie ar putea consta în faptul că insulinoterapia asigură o echilibrare metabolică mai bună, cu regresia sau chiar remisia steatozei (,ficat în armonică”).

Keywords: type 2 diabetes mellitus, hepatic steatosis, insulin therapy oral antidiabetics

\section{Introduction}

Hepatic steatosis defines lipid accumulation in the liver, exceeding $5.5 \%$ of its weight $[3,4,6]$, or when $5 \%$ of the hepatocytes contain typical lipid macrovesicles at the histological examination.

Concerning the prevalence, the Third National Study regarding health and nutrition (NAHNES) has evaluated the prevalence of NAFLD (nonalcoholic fatty liver disease- hepatic steatosis) from 1988 until 1994, in the United States, based on ultrasonography data, in the case of 12,454 adults. They estimated that 28.8 millions of adults could be diagnosed with NAFLD in the United States; prevalence would correspond to $19 \%$ [11]; NAFLD appears with a higher prevalence in the case of hispanic - american population, compared to the non-hispanic population. NAFLD was associated independently with insulin resistance and diabetes mellitus, but also among people without diabetes, with dyslipidaemia and obesity; the study confirmed that NAFLD is more common in the case of men $[9,11,15,17,18]$. NAFLD prevalence in the Italian Dionysos study, in case of adults with and without suspected hepatic disease, was of $25 \%$, respectively $20 \%$, using the echographic -ultrasonographic identification method $[2,4,5,12]$. NAFLD prevalence in Japan has increased 2.4 times, from $12.6 \%$ in 1989 to $30.3 \%$ in $1998[5,10]$. A lower prevalence was reported in India, using ultrasound for NAFLD identification: NAFLD prevalence was of $18.9 \%$ in the case of adults over the age of 20 years, with a higher prevalence in the case of men than women $(24.6 \%$ vs $13.6 \%)$ [1, 20, 24]. NAFLD prevalence, diagnosed with ultrasound, was of $69.4 \%$ in the case of 180 patients with DM type 2; NAFLD has been associated with obesity, hypertriglyceridemia and increased ALAT (alaninamino-transferase) [12, 23]; in another study, NAFLD was highlighted by ultrasound in a proportion of $62.2 \%$ in the case of 204 patients with DM type 2. In the case of these patients, NAFLD was confirmed by biopsy in $87 \%$ of the patients and the subsequent histological examination confirmed it in $54.11 \%$ of them. In the case of the same patients, steatohepatitis and fibrosis were found in $38.9 \%$, respectively $23.2 \%$ of patients $[5,19]$. Regarding pathogenesis, the major biochemical event in NAFLD is the accumulation of triacylglycerols 
(TAGs) in hepatocytes. TAGs can accumulate in hepatocyte from various sources: released from chylomicrons in the liver, where they can be secreted as lipoproteins, from fatty acids and glycerol in the liver. The necessary fatty acids can arise from the pool of non-esterified fatty acids from the plasma, being synthesized within the novo hepatic lipogenesis.

When there is insulin resistance - the sign of metabolic syndrome - there is no insulin-dependent lipase regulation, leading ultimately to an increased lipolysis and an increased flux of free fatty acids (FFA) in plasma, from adipocytes [8].

Hyperglycaemia (and hyperinsulinemia) induces SREBP-1c (sterol regulatory element binding protein) and ChREBP (transcriptional regulator of glucose and lipid metabolism) in the liver, and these transcription factors activate subsequently the genes that are necessary for lipogenesis, resulting the novo hepatic lipogenesis [21]. FFA beta-oxidation is increased in the case of patients with NAFLD. Oxidation cannot exceed the increased production of hepatic TAGs. Excessive oxidation of FFA may generate oxidative stress, resulting in the transition of NAFLD to steatohepatitis (NASH) $[4,21]$. This pathological biochemical pathway provides the reason why there is a close association between fatty liver and insulin resistance, correlated with obesity $[16,19,20]$. FFA are directly hepatotoxic, and the level of FFA is increased in liver steatosis (fatty liver), correlating with the severity of the disease $[15,16,22,24]$. Patients with severe fibrosis (demonstrated by liver biopsy) have a significantly higher FFA serum concentration than those without severe fibrosis $[9,16]$. Saturated FFA (e.g. palmitate) are more hepatotoxic than the unsaturated ones (ex. palmitoleate). Palmitoleate, known as a lipokine, has been demonstrated to diminish hepatic steatosis and does not induce stress or apoptosis at the level of hepatocytes' endoplasmic reticulum. Also, it decreases the effects induced by palmitate. It is assumed that the difference of toxicity between saturated and unsaturated FFA is because unsaturated FFA are more easily esterified in neutral triglycerides $[15,20,25,32]$.

The deterioration of the hepatocytes capacity to use FFA, to incorporate and export TAGs, contributes to the development of steatohepatitis, and hepatic injury is furtherly accentuated by pathological oxidation of FFA and alteration of cell membrane composition [22]. Lipotoxicity induces hepatocellular apoptosis, the activation of Kupffer cells, alteration of insulin sensitivity and insulin resistance, activation of Ito cells, with subsequent fibrosis. These pathological processes may lead eventually to cirrhosis $[8,14$, 22, 23].

Ultrasound exploration is very sensitive in the detection of hepatic steatosis, but the specificity is relatively low. Suggestive modifications for steatosis are represented by the increased volume of the liver, increased echogenicity of the parenchyma and ultrasound attenuation in subcapsular layers.

In the case of patients with type $2 \mathrm{DM}$, hepatic steatosis is present in a much higher proportion than in healthy people. Throughout this study, we have evaluated the presence of steatosis (by ultrasound examination) in patients with type $2 \mathrm{DM}$, and whether this may be correlated with the type of patients' treatment, either oral antidiabetics (OAD), or insulin therapy \pm OAD. In the same time, steatosis has been correlated with the nutritional status, metabolic control and lipidic profile.

\section{Materials and Methods}

\section{Study design}

We enrolled 94 patients with type 2 DM, being either treated with insulin and oral antidiabetics (OAD), or only with OAD for at least three years, examined by ultrasound at Municipal Clinical Hospital "Dr. Gavril Curteanu" Oradea, Romania between February and April 2017. All patients signed the informed consent according to the World Medical Association Declaration of Helsinki, Ethical principles for medical research involving human subjects (2013) and we also achieved the approval of the Ethics Committee of the Faculty of Medicine and Pharmacy, University of Oradea, Romania, to perform the clinical study. Out of these patients we selected the ones who had the characteristic ultrasound appearance of hepatic steatosis; the alcoholic and/or viral steatosis was excluded. Of the 27 excluded diabetic patients, 8 exhibited hepatopathy of viral and/or alcoholic aetiology, and the other 19 had echographic normoechogenic liver; 16 of these patients were insulin dependent (84\%). 67 patients were selected, representing $71.2 \%$ of the total examined patients. They were divided into two groups, depending on the followed antidiabetic therapy: Group 1 - oral therapy (OAD) with 36 de patients, Group 2 - the Insulin group (patients that received insulin \pm OAD) with 31 patients.

The length of the diagnosis of diabetes varied between 1 to 40 years, the medium length of the disease being 9.5 years.

In Group 1, oral antidiabetics were used as follows: from Biguanide class - metformin - 10 cases (doses between 500 and $2000 \mathrm{mg} /$ day, most of the patients with $2000 \mathrm{mg} /$ day), from the sulfonylurea class gliclazide - 8 cases (alone or in combination with metformin; usual dosage between 60 - $120 \mathrm{mg} /$ day); glimepiride - 8 cases (average dose 6 - $9 \mathrm{mg} /$ day), glibenclamide associated with metformin - 4 cases (in a combined pill, metformin $400 \mathrm{mg} / \mathrm{glibenclamide}$ $2.5 \mathrm{mg}$ per tablet, usual dose 1 - 3 tablets/day), glyburide associated with metformin - 4 cases (in this combined pill, glyburide $1.25-2.5 \mathrm{mg}$ and metformin 250 - 
FARMACIA, 2018, Vol. 66, 4

$500 \mathrm{mg}$, usual dose 1 - 3 tablets/day). Patients used oral antidiabetics for an average period of 7.5 years. Patients in Group 2 used different types of insulin: long-acting insulin (Glargine ${ }^{\circledR}$ and Detemir ${ }^{\circledR}$ ), Mixed insulins and Rapid (short acting) insulins. 85\% of patients were on basal, long-acting Insulin Glargine ${ }^{\circledR}$ for a period varying from 1 year to 8 years, $10 \%$ of patients had a basal insulin and boluses of rapid insulin - 3 times a day for minimum 1 year and 5\% of patients used mixed insulin (short-acting and medium-acting period) for $1-1.5$ years.

Biochemical analysis

All patients were assessed: blood pressure (BP), abdominal circumference (metabolic syndrome marker), weight status expressed by BMI (body mass index), lipid profile $(\mathrm{LDL}=$ low density lipoproteins, $\mathrm{HDL}=$ high density lipoproteins - cholesterol-CST, VLDL = very low density lipoproteins, triglycerides), uric acid, hepatic function $(\mathrm{GOT}=$ glutamic-oxalacetic transaminase, GPT = glutamic-piruvic transaminase, GGT = gamma glutamil transpeptidase, ALP = alkaline phosphatase, total and direct bilirubin), metabolic

control of diabetes mellitus - expressed as fasting blood glucose and glycosylated haemoglobin.

Statistical analysis

The statistical analysis was done using EPIINFO, version 6.0, program of the Center for Disease Control and Prevention - CDC from Atlanta and WHO (World Health Organisation), adapted to the medical statistics processing and SPSS 19. We calculated the average values of the parameters, the frequency intervals, standard deviations, statistical significance tests by the Student method (test $t$ ) and $\chi^{2}$. The charts were made using the Harvard Graphic programme.

\section{Results and Discussion}

The two groups included in the study showed homogeneity regarding the age, sex distribution and background.

In Group 1 patients were aged between 46 - 85 years, the average being of 65.64 years, and in Group 2, ages were between 46 - 81 years, the average being of 65.10 years $(p=0.910)$ (Table I).

Table I

Groups characteristics

\begin{tabular}{|l|c|c|}
\hline \multicolumn{1}{|c|}{ Parameter } & Group 1 & Group 2 \\
\hline Age (years) & $65.64 \pm 7.51$ & $65.10 \pm 5.53$ \\
\hline Gender (female/male) & $69.44 \% / 30.56 \%$ & $70.97 \% / 29.03 \%$ \\
\hline Environment (urban/rural) & $58.33 \% / 41.67 \%$ & $51.61 \% / 48.39 \%$ \\
\hline
\end{tabular}

Women predominated in both groups $(69.44 \%$, respectively $70.97 \%)(p=0.737)$ and over $50 \%$ came from rural areas $(68.33 \%$, respectively $51.61 \%)(\mathrm{p}=$ 0.179 ).

The assessment of the body mass index (BMI), with the formula $\mathrm{G}(\mathrm{kg}) / \mathrm{I}^{2}(\mathrm{~m})$ revealed the results depicted in Figure 1.

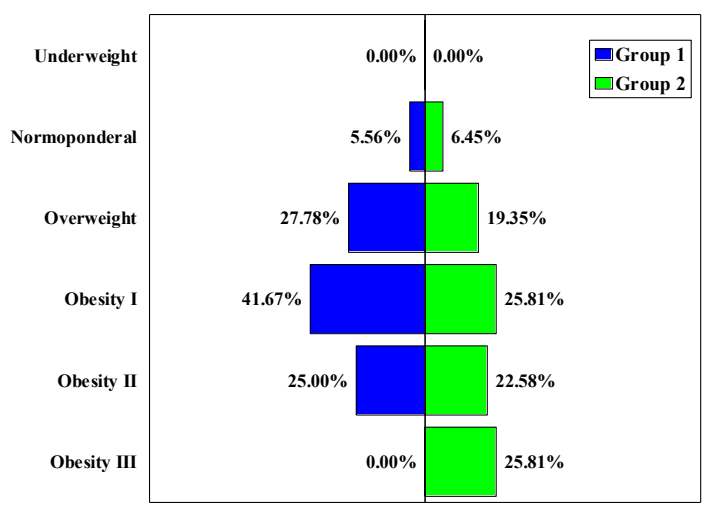

Figure 1.

Determination of obesity status

Obesity was more common in the Insulin Group (2), but statistically insignificant, and lipidic parameters also did not show statistically significant differences. In Group 1 obesity was present in $66.68 \%$ of patients, and in Group 2 in $74.19 \%(p=0.056)$. We remark the fact that morbid obesity (BMI $>40 \mathrm{~kg} / \mathrm{m}^{2}$ ) was not present in any patients from the OAD treated Group, but it was present in $25.81 \%$ of the Insulin Group (Figure 1).

We remark the fact that all parameters of the lipidic profile in the Insulin Group (Group 2) had lower values than in the ADO group (Group 1), but without significant differences $(\mathrm{p}>0.05)$ (Figure 2).

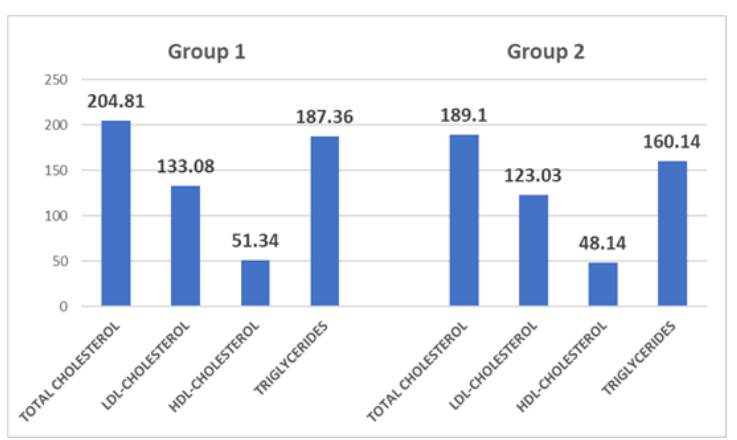

Figure 2.

Lipidic profile

In Group 1 fasting blood glucose ranged from 90 and $354 \mathrm{mg} / \mathrm{dL}$, with an average of $156.92 \mathrm{mg} / \mathrm{dL}$, and in Group 2 fasting blood glucose ranged between 75 and $446 \mathrm{mg} / \mathrm{dL}$ with an average of $192.58 \mathrm{mg} / \mathrm{dL}$ ( $\mathrm{p}=$ 0.073 ). The metabolic control was evaluated through glycosylated haemoglobin (Hb A1c).

In Group 1 unbalanced and very unbalanced metabolic control (elevated HbA1c) was recorded in $16.67 \%$ of 
the patients, a significantly lower percentage than in Group $2(35.48 \%)(p=0.003)$ (Figure 3).

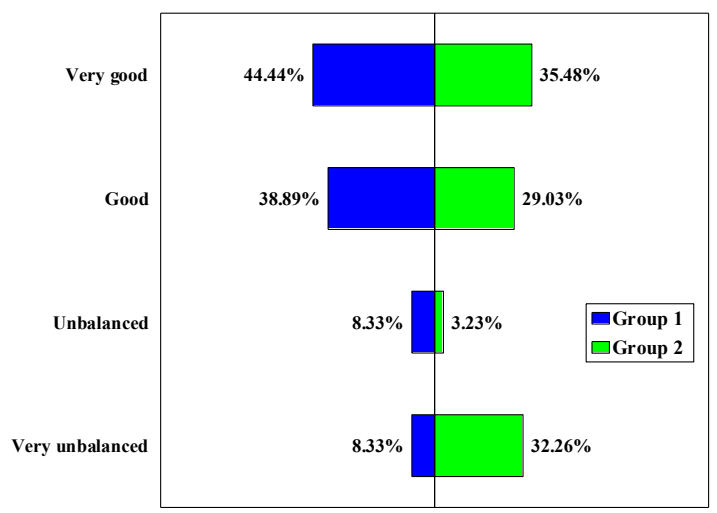

Figure 3.

Glycosylated haemoglobin levels

In Group $1,77.78 \%$ of patients had grade II and III of hepatic steatosis, a significantly higher percentage than in Group $2(35.48 \%)(p<0.001)$ (Figure 4).

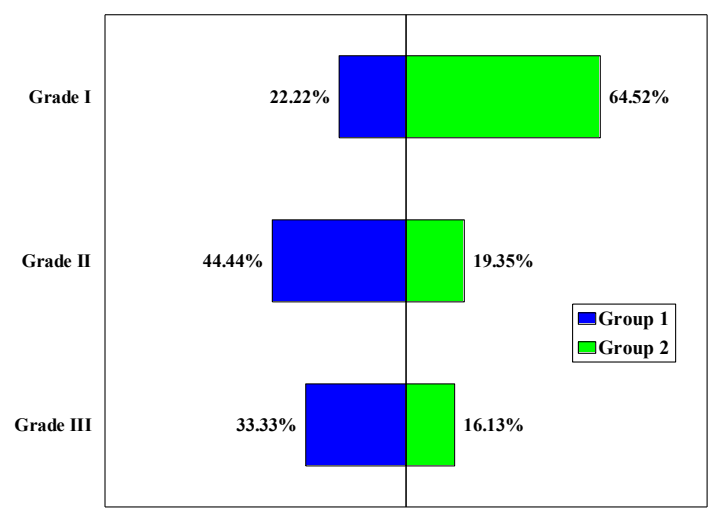

Figure 4.

Hepatic steatosis grade

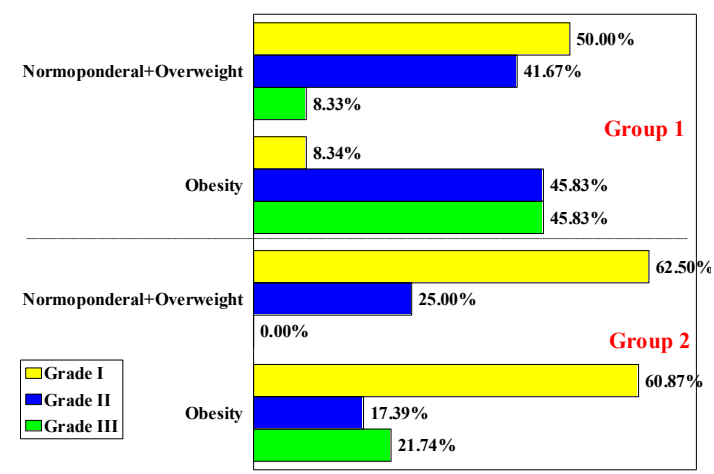

Figure 5.

The prevalence of hepatic steatosis depending on the ponderal status of patients

In the case of normal and overweight patients, the prevalence of grade II and III of hepatic steatosis in Group 1 was of $50.00 \%$, a significantly higher percentage than in Group $2(25.00 \%)(p<0.001)$. In the case of obese patients the prevalence of grade
II and III of hepatic steatosis was of $91.67 \%$ in Group 1, a significantly higher percent than in the Insulin Group (group 2). (39.13\%) ( $<<0.001)$ (Figure 5).

In the case of patients with good and very good metabolic control, the prevalence of grade II and III of hepatic steatosis in Group 1 was of $73.33 \%$, a significantly higher percent than in Group 2 $(25.00 \%)(\mathrm{p}<0.001)$ (Figure 6).

In the case of patients with unbalanced metabolic control, the prevalence of grade II and III of hepatic in Group 1 was of $100 \%$, a significantly higher percent compared to Group $2(54.55 \%)(p<0.001)$.

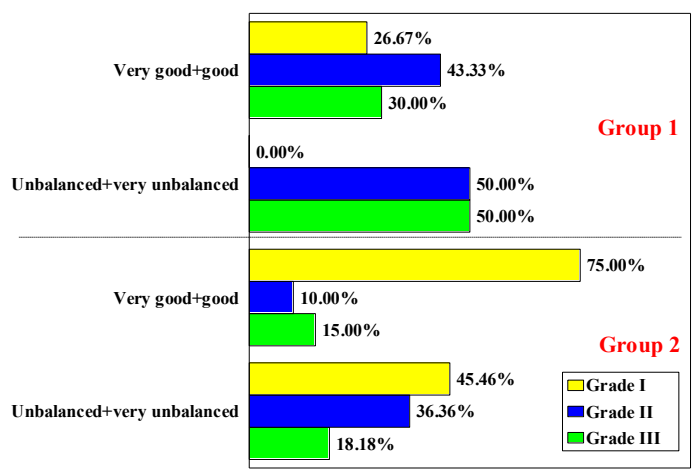

Figure 6.

The prevalence of hepatic steatosis depending on the metabolic control

In the case of patients with normal total cholesterol, the prevalence of grade II and III of hepatic steatosis in Group 1 was of $78.57 \%$, a significantly higher percent than in Group $2(27.78 \%)(\mathrm{p}<0.001)$ (Figure 7).

In the case of patients with high (elevated) total cholesterol, prevalence of grade II and III of hepatic steatosis in Group 1 was of $77.27 \%$, a significantly higher percent compared to Group $2(46.15 \%)$ ( $\mathrm{p}<$ 0.001).

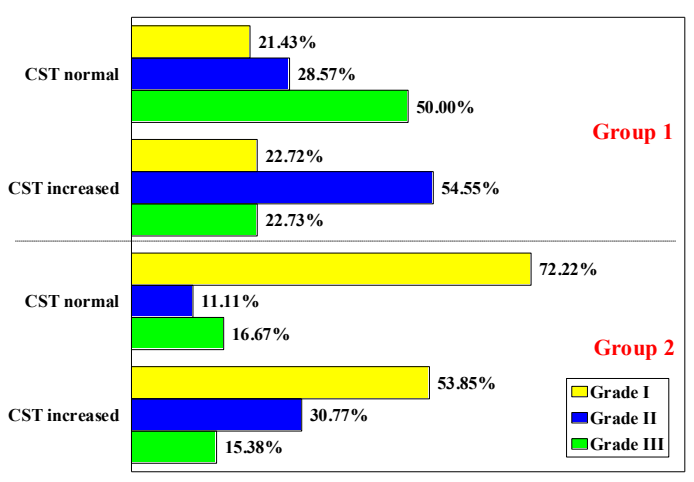

Figure 7.

The prevalence of steatosis severity depending on lipid profile (CST- cholesterol)

In the case of patients with normal LDL-cholesterol, the prevalence of grade II and III of hepatic steatosis in OAD Group was of $75.00 \%$, a significantly higher 
FARMACIA, 2018, Vol. 66, 4

percent than in the Insulin Group $(33.33 \%)(p<0.001)$ (Figure 8).

In the case of patients with high (elevated) LDLcholesterol, prevalence of grade II and III of hepatic steatosis in Group 1 was of $78.57 \%$, a significantly higher percent than in Group $2(36.36 \%)(p<0.001)$.

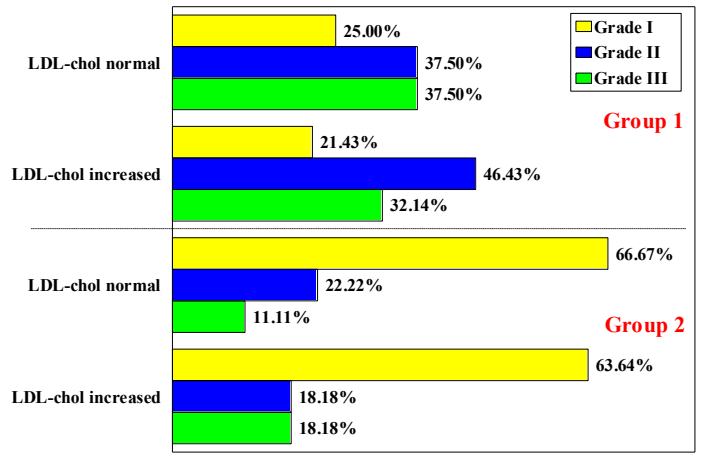

Figure 8.

The prevalence of steatosis severity depending on lipidic profile (LDL- cholesterol)

In the case of patients with normal HDL- cholesterol, the prevalence of grade II and III of hepatic steatosis in Group 1 was of $77.27 \%$, a significantly higher percent than in Group $2(30.77 \%)(p<0.001)$.

In the case of patients with low HDL- cholesterol, prevalence of grade II and III of hepatic steatosis in Group 1 was of $78.57 \%$, a significantly higher percent compared to Group $2(38.89 \%)(p<0.001)$.

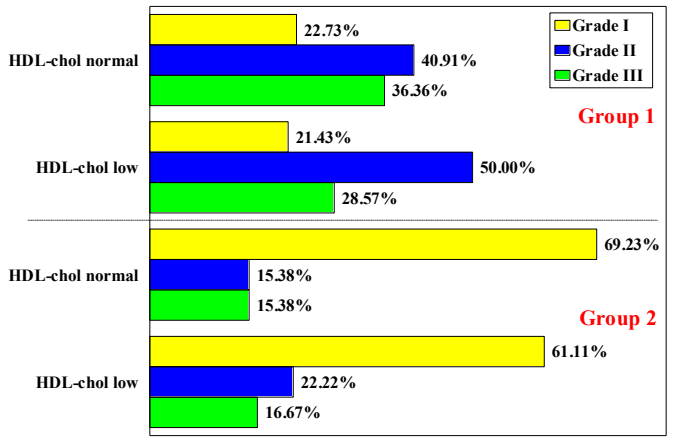

Figure 9.

The prevalence of steatosis severity depending on lipidic profile (HDL- cholesterol)

In the case of patients with normal triglycerides, the prevalence of grade II and III of hepatic steatosis in OAD group was of $64.71 \%$, a significantly higher percent than in the insulin group $(28.57 \%)(p<0.001)$ (Figure 9).

In the case of patients with increased triglycerides, prevalence of grade II and III of hepatic steatosis in Group 1 was of $89.47 \%$, a significantly higher percent compared to Group $2(41.18 \%)(p<0.001)$.

One of the most important metabolic effects of insulin is the suppression of lipolysis. The effect is mediated by the inhibition of hormone-sensitive lipase, which is accomplished by a double mechanism, as follows: insulin inhibits re-esterification of free fatty acids in the liver, a process that is reflected by the low rate of VLDL synthesis; in the same time it inhibits their oxidation in the liver, but also in the skeletal and cardiac muscle; these processes are achieved through the antilipolytic effect, that leads to the decrease of free plasma fatty acid availability [7, 13, 14].

A study performed in case of diabetic patients shows that insulin, administered for a long term, determines the decrease of hepatic steatosis, transaminases, probably by lowering blood glucose and influencing lipid metabolism [9].

\section{Conclusions}

It is necessary and important to diagnose NAFLD by routine, because removal of the cause leads to the reversibility of steatosis.

Patients with untreated NAFLD (from the perspective of etiological factor) may develop, in half of the cases, progressive fibrosis, and one sixth of them may develop cirrhosis.

Patients with type 2 DM exhibit hepatic steatosis assessed by ultrasound - in a statistically significant percentage than healthy people, and the therapy used for glycaemic control has influences on the degree of hepatic steatosis.

In our study, patients treated with insulin (Group 2), for at least three years, exhibited hepatic steatosis in a statistically significant lower percent than patients treated with OAD. This finding is maintained after correlation with weight status or metabolic control. Regarding the weight status (body mass index), the degree of metabolic control and lipidic profile, the prevalence of hepatic steatosis of grade II and III (more severe) was significantly higher in OAD patients (Group 1) than in those with insulin (Group 2).

Although patients from Group 1 were treated with different $\mathrm{OAD}$ and patients from Group 2 were treated with different insulin types, the final results were not influenced: patients from Group 2 showing a lower prevalence and severity of steatosis.

The explanation of the better results, in the case of patients treated with insulin, could be that insulin therapy provides a better metabolic balance, with regression or even remission of steatosis ("harmonic liver").

\section{References}

1. Amarapurkar D, Kamani P, Patel N, Gupte P, Kumar P, Agal S, Baijal R, Lala S, Chaudhary D, Deshpande A, Prevalence of non-alcoholic fatty liver disease: population based study. Ann Hepatol., 2007; 6: 161-163.

2. Bedogni G, Miglioli L, Masutti F, Tiribelli C, Marchesini G, Bellentani S, Prevalence of and risk 
factors for nonalcoholic fatty liver disease: the Dionysos nutrition and liver study. Hepatology, 2005; 42: 44-52.

3. Browning JD, Szczepaniak LS, Dobbins R, Nuremberg P, Horton JD, Cohen JC, Grundy SM, Hobbs HH, Prevalence of hepatic steatosis in an urban population in the United States: impact of ethnicity. Hepatology, 2004; 40: 1387-1395.

4. Bugianesi E, Leone N, Vanni E, Marchesini G, Brunello F, Carucci P, Musso A, De Paolis P, Capussotti L, Salizzoni M, Rizzetto M, Expanding the natural history of nonalcoholic steatohepatitis: from cryptogenic cirrhosis to hepatocellular carcinoma. Gastroenterology, 2002; 123(1):134-140.

5. Bugianesi E, Moscatiello S, Ciaravella MF, Marchesini $\mathrm{G}$, Insulin resistance in nonalcoholic fatty liver disease. Curr Pharm Des., 2010; 16: 1941-1951.

6. Cao H, Gerhold K, Mayers JR, Wiest MM, Watkins SM, Hotamisligil GS, Identification of a lipokine, a lipid hormone linking adipose tissue to systemic metabolism. Cell, 2008; 134: 933-944.

7. De Alwis NMW, Day CP, Non-alcoholic fatty liver disease. The mist gradually clears. $J$ of Hepatology, 2008; 48(1): 104-112.

8. Donnelly KL, Smith CI, Schwarzenberg SJ, Jessurun J, Boldt MD, Parks EJ, Sources of fatty acids stored in liver and secreted via lipoproteins in patients with nonalcoholic fatty liver disease. $J$ Clin Invest., 2005; 115: 1343-1351.

9. Hossain P, Kawar B, El Nahas M, Obesity and diabetes. NEngl J Med., 2007; 356(3): 213-215.

10. Kojima S, Watanabe N, Numata M, Ogawa T, Increase in the prevalence of fatty liver in Japan over the past 12 years: analysis of clinical background. $J$ Gastroenterol., 2003; 38: 954-961.

11. Lazo M, Hernaez R, Eberhardt MS, Bonekamp S, Kamel I, Guallar E, Koteish A, Brancati FL, Clark JM, Prevalence of nonalcoholic fatty liver disease in the United States: the Third National Health and Nutrition Examination Survey, 1988-1994. Am J Epidemiol., 2013; 178: 38-45.

12. Leite NC, Salles GF, Araujo AL, Villela-Nogueira CA, Cardoso CR. Prevalence and associated factors of non-alcoholic fatty liver disease in patients with type-2 diabetes mellitus. Liver Int., 2009; 29:113-119.

13. Li ZZ, Berk M, McIntyre TM, Feldstein AE, Hepatic lipid partitioning and liver damage in nonalcoholic fatty liver disease: role of stearoyl-CoA desaturase. J Biol Chem., 2009; 284: 5637-5644.
14. Listenberger LL, Han X, Lewis SE, Cases S, Farese RV, Ory DS, Schaffer JE, Triglyceride accumulation protects against fatty acid-induced lipotoxicity. Proc Natl Acad Sci USA, 2003; 100: 3077-3082.

15. Lupașcu FG, Avram I, Confederat L, Constantin SM, Stan CJ, Lupuşoru EC, Sava A, Profire L, Biological evaluation of chitosan- antidiabetic drug formulations for the treatment of diabetes mellitus. Farmacia, 2017; 65(4): 508-514.

16. Nehra V, Angulo P, Buchman AL, Lindor KD, Nutritional and metabolic considerations in the etiology of nonalcoholic steatohepatitis. Dig Dis Sci., 2001; 46: 2347-2352.

17. Pallag A, Paşca B, Jurca T, Suciu R, Nemeth S, Vicaş L, Comparative histo-anatomical researches on the vegetative organs and assessment of antioxidant capacity of two species from Equisetum genus. Farmacia, 2016; 64(3): 372-377.

18. Pavel IZ, Pârvu AE, Dehelean CA, Vlasez L, Csuk R, Muntean DM, Assessment of the antioxidant effect of a maslinic acid derivate in an experimental model of acute inflammation. Farmacia, 2017; 65(3): 390-395.

19. Prashanth M, Ganesh HK, Vima MV, John M, Bandgar T, Joshi SR, Shah SR, Rathi PM, Joshi AS, Thakkar $\mathrm{H}$, Prevalence of nonalcoholic fatty liver disease in patients with type 2 diabetes mellitus. J Assoc Physicians India, 2009; 57: 205-210.

20. Roden M, Mechanisms of disease: hepatic steatosis in type 2 diabetes-pathogenesis and clinical relevance. Nat Clin Pract Endocrinol Metab., 2006; 2: 335-348.

21. Schwarz JM, Linfoot P, Dare D, Aghajanian K, Hepatic de novo lipogenesis in normoinsulinemic and hyperinsulinemic subjects consuming high-fat, low-carbohydrate and low-fat, high-carbohydrate isoenergetic diets. Am J Clin Nutr., 2003; 77: 43-50.

22. Trauner M, Arrese M, Wagner M. Fatty liver and lipotoxicity. Biochim Biophys Acta, 2010; 1801: 299-310.

23. Velescu BȘ, Anuța V, Aldea A, Jinga M, Cobeleschi PC, Zbârcea CE, Uivarosi V, Evaluation of protective effects of quercetin and vanadyl sulphate in alloxan induced diabetes model. Farmacia, 2017; 65(2): 200-206.

24. Wei Y, Wang D, Topczewski F, Pagliassotti MJ, Saturated fatty acids induce endoplasmic reticulum stress and apoptosis independently of ceramide in liver cells. Am J Physiol Endocrinol Metab., 2006; 291: 275-281. 